\title{
An Inquiry Safari: What Can We Learn From Skulls?
}

\author{
Norman Thomson • Seri Chapman Beall
}

Published online: 18 January 2008

(C) Springer Science + Business Media, LLC 2007

\begin{abstract}
In this article, we describe an 8- to 10-day inquiry safari designed for middle/high school students to investigate hominid evolution using replica skulls of extant and extinct vertebrates. Students begin the unit using their own skulls and proceed to use the replica skulls of extant vertebrates to construct an understanding of how skulls can be used to interpret and infer diets, dentition, dental formulae, bipedal or quadrupedal locomotion, and the social structure of animals. They are then able to use this knowledge to construct similar inferences for extinct fossil hominids. Using radiometric dating data, the students develop possible phylogenetic pathways for hominid evolution. The lessons promote the use of inquiry skills including journaling, observing, drawing, puzzle-making, using taxonomic keys, and investigating into deep geological time.
\end{abstract}

Keywords Inquiry safari · Middle/high school students ·

Hominid evolution · Skulls $\cdot$ Extant vertebrates

It is a great time to be a young biologist! In our curriculum, An Inquiry Safari: What Can We Learn from Skulls? (Fig. 1), we invite students to engage in exciting, thoughtful conversations about hominid evolution. Throughout their learning process, students develop into budding paleoanthropologists during which they create questions, generate

\section{N. Thomson $(\triangle)$}

Mathematics and Science Education, University of Georgia,

212 Aderhold Hall,

Athens, GA 30602, USA

e-mail: nthomson@uga.edu

S. Chapman Beall

Dacula Middle School,

Dacula, GA, USA

e-mail: schapman@uga.edu evidence, develop scientific explanations, and share their interpretations of the story of our hominid past. Our curriculum is based on five philosophical tenets (Fig. 2) and supported by research in science (Freeman and Herron 2007; Futuyma 2005) and science education (National Research Council 2000, 2005). With respect to learning evolution, we wish to make it a hands-on experience with an overall theoretical framework of retrodictive inquiry. In geology and evolutionary biology, a prediction is a specification of what will happen whereas retrodiction is a specification of what did happen (Ben-Ari 2005). We have chosen to focus on hominid evolution because (1) it is one of the most controversial and misunderstood topics in science today; (2) the hominid fossil record has recently become particularly rich, providing a framework for constructing phylogenies of human evolution; (3) skulls are small and transportable (vs whale bones), ideal for hands-on observations and measurements (currently at least 92 measurements are used in fossil skull interpretations, see Cameron and Groves 2004); and (4) skulls can tell us a great deal about the life and evolution of species/individual organisms.

We have found that students are fascinated by the opportunity to handle life-size fossil replicas and to find out the stories that can emerge from them. Students gain an understanding of macroevolution (evolution occurring through deep time) vs microevolution, as radiometric dating of observed skulls reveals the magnitude of geologic time. Skulls offer permanent pieces of evidence, but the interpretation of their changing phylogenies or evolutionary paths provides opportunities for rich discussion about how science knowledge is constructed and modified. Finally, the five National Standards for science inquiry guide our curriculum: questioning, observation, evidence, explanation, reflection, and communication. 


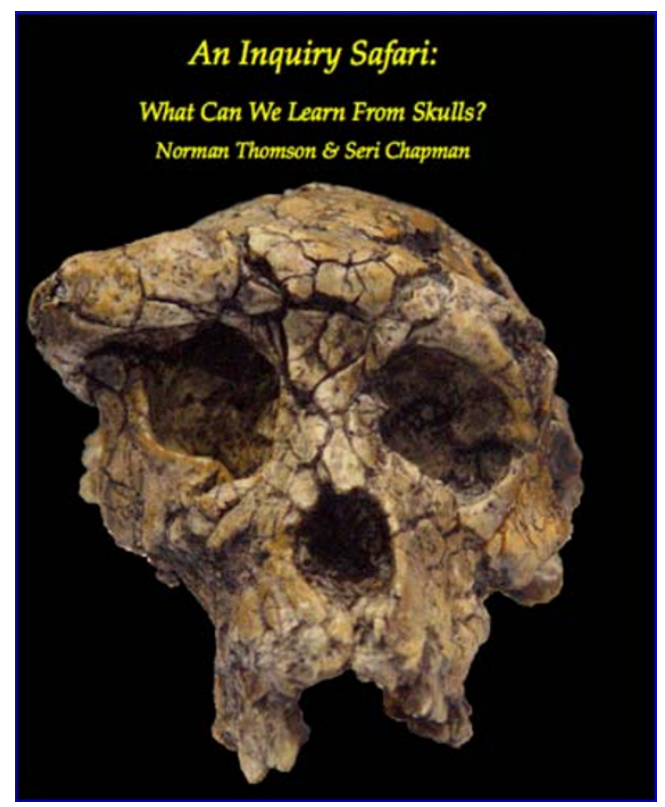

Fig. 1 The cover of our activity book
Initial inquiries challenge students to become nascent mammalogists (experts in regard to extant species), establishing a foundation for later inquiries as paleoanthropologists (experts on extinct species). In this phase of the safari, students are introduced to retrodictive inquiry. Our safari spans approximately 8 to 10 teaching days and is outlined below.

Safari day 1: Learning how to conduct reflective journaling is an essential aspect of doing science. We begin our unit with emphasizing the importance of making daily entries during the safari. We begin with examples of field notes made by ethologists in which students enact an experience of Bill Weber (Weber and Vedder 2001) encountering Brutus, a male silverback gorilla (see Thomson and Chapman 2004). We want students to appreciate that another scientist should be able reconstruct their record of observations through wellwritten descriptions and sketches. Also, on
Fig. 2 An inquiry safari: the theoretical underpinnings of the curriculum
Scaffolded Inquiry: In this curriculum, we provide students with the necessary scaffolds to direct and support learning, while giving flexibility for student choice and questioning. Scaffolding student learning involves setting high expectations for students, while providing helpful benchmarks, connections to prior knowledge, debriefing sessions and frequent assessments to guide students to reaching the final goal. Inquiry is a method of teaching and learning that engages students in the learning process and encourages students to ask and answer their own questions.

Discipline Specific Instruction: Students learn science concepts in a discipline specific environment because they learn through the lens of real scientists, and in simulated field experiences. In part one of the curriculum, students step into the shoes of Dian Fossey, a famous primatologist who studied mountain gorillas. Students learn about gorillas, animal behavior, conservation issues, and process skills. In the second part of the curriculum, students take on the role of paleoanthropoligists, becoming experts regarding the anatomy of extant and extinct skulls to infer hominid evolution. Students accommodate new knowledge in this rich and authentic environment of experiences.

Explicitly Teaching Nature of Science (NOS) Concepts: The lessons in this curriculum encourage conversation regarding the nature of science concepts. So, students not only engage in the process of scientific inquiry, but they also "inquire into inquiry." Students participate in the scientific process with making observation and inferences, collecting and analyzing data, creating models to critique and perfect, and presenting findings to peer audiences. Students also explicitly discuss and reflect on "the ways of doing science" and how and why scientific knowledge is established.

Reflection and Metacognition: Students are given the time to turn ideas over in their minds (metacognition) and grapple with new material (science in the making). The reflective aspect of the learning process encourages participants to relate their scientific experiences with their conceptions of NOS and re-evaluate their understanding of the content. The explicit conversations that transpire allow participants to clarify, define and redefine their conceptual frameworks.

Modeling: Creating models (physical and mental), working with models, and using models as conceptual frameworks for generating and answering questions are important scientific skills, as models and using models encourage close observation, questioning, dialogue, critiquing, and predictive and retrodictive inquiry. Students create models of gorilla motion and hominid evolution to facilitate deeper understanding of the mental models used to engage in scientific inquiry that form the evolutionary framework for studying organisms.

Evolution: Dobzhansky wrote to the American Biology Teacher in 1973, stating, [s]een in the light of evolution, biology is, perhaps, intellectually the most satisfying and inspiring science. Without that light it becomes a pile of sundry facts-some of them interesting or curious but making no meaningful picture as a whole (p. 129). In line with this assertion, we emphasize the teaching and learning of evolution to help students build the necessary framework for learning additional scientific concepts. 
the first day, students are randomly grouped to begin investigating a forensic bone collection set (Sherlock Bones, Wards 2008) to determine the sex, height, race, and approximate age of the skeleton at the time of death. We emphasize that the same evidence and knowledge crime scene investigators use to reliably reconstruct past events are used by paleoanthropologists and that their data is just as reliable. Finally, we explain to the students that the culmination of the safari will be an "international evolution symposium" for students to present their own research investigations and provide slide presentations supporting and/or refuting six current hypotheses (Lewin and Foley 2004) being discussed for the origins of bipedalism: (1) energyefficient locomotion (two vs four legs), (2) food gathering (free hands), (3) predator avoidance (seeing over grass), (4) provisioning offspring (carry babies), (5) freeing the hands (making tools/weapons), (6) tracking migrating herds (long distance travel). A seventh, fast running, was recently rejected.

Safari day 2: Students begin the day completing the identification of the forensic skeleton. We begin experiences as mammalogists in an activity, "What can we learn from our own skulls?" A teacher-directed activity guides students in brainstorming the functions of our bones, skull, and teeth. Students observe, count, and describe a friend's teeth. Data (each individual's number of teeth) is displayed in a data chart, showing the individual variation in teeth numbers that exists during the adolescent years of development (Table 1). This includes a discussion of the kinds of teeth along with why there is selection for two sets of teeth, deciduous and permanent, and the current hypotheses for the rapid ongoing evolution of the human jaw (Lucas 2004). Students then eat and describe the ingestion of a cracker as a segue to identifying the names, forms, and functions of the different mammalian teeth (incisors for biting or cutting, canines for piercing and tearing, and molars for crushing, grinding, or shearing). As a finale to this safari day, students learn how to construct a dental formula, which is the ratio, number, and
Table 1 Chart showing data for the distribution of total numbers of teeth students had in two classes

\begin{tabular}{ll}
\hline Number of teeth & Number of students \\
\hline 32 & 1 \\
31 & 0 \\
30 & 1 \\
29 & 2 \\
28 & 19 \\
27 & 3 \\
26 & 4 \\
25 & 1 \\
24 & 1 \\
23 & 1 \\
22 & 1 \\
\hline
\end{tabular}

types of teeth, comparing the upper and lower jaws.

Safari days 3 and 4: The framework of vocabulary and investigative skills that are established on the first 2 safari days provide a familiar context by which students can now critically compare and contrast two extant skulls (carnivore, omnivore or herbivore) from a "reference collection" of specimens. Our current reference collection of extant skulls includes Homo sapiens (human), Gorilla gorilla (lowland gorilla, male and female), Pan troglodytes (chimpanzee), Pongo pygmaeus (orangutan), Puma concolor (mountain lion), Felis domesticus (domestic cat), Canus latrans (coyote), Canus lupus familiaris (dog), Equus caballus (horse), and Odocoileus virginianus (deer), and Alligator mississippiensis (American alligator) as a reptilian outlier. Students create scaled drawings of their two selected skulls, making observations, counting the number of teeth, identifying the specific types of teeth, stating sketch magnification, deducing dental formulae, and determining the working surface area of an incisor or canine vs a molar tooth. Students make inferences in regard to diet, age, sex, intelligence, social structure, locomotive orientation (biped or quadruped), etc., of the observed individual 
(Fig. 3). Students share their data and logical inferences with others in a facilitated classroom discussion, emulating scientific discourse and communication. From here, students experience a smooth transition to the next level of conceptual development, applying practiced knowledge and skills concerning known extant models to the less familiar world of extinct hominids through retrodictive inquiry.

Safari day 5: First, we create an authentic learning environment for our student paleoanthropologists, similar in effect to the questionevoking aura of a crime scene. Students encounter a fossil dig (Gibbons 2006). For this activity, we made two digital images of each of our fossil skulls taken from different views and used Photoshop to create transparencies which were placed on PowerPoint slides with background soil colors representative of the location where the fossil was found in Africa. Each image was made into a 30 -piece $(65$ pieces, $8 \times$ 11 in.) puzzle through a local camera shop. We first mixed the 2 puzzles together into 60 piece units that were given to groups of 4 students (we now have 20 puzzles). However, this became a time-consuming challenge in which too much effort was used by student groups (along with great individual differences) for puzzle assembly. We now have each student (depending upon class size) select an unknown puzzle. The fossil pieces are connected together based on morphological clues (Fig. 4a,b) resulting in the reconstruction of an extinct hominid skull (Sahelanthropus tchadensis, Australopithecus afaranesis, Paranthropus boisei, Australopithecus africanus, Homo erectus, Homo ergaster, Homo neanderthalensis, or Homo floresiensis) and Piltdown man (our source of skulls has been http://www. boneclones.com). (We have made puzzles for our Homo habilis skull, but are now using this skull to challenge students in the reconstruction of their phylogenetic tree explained in safari day 7). Each student next identifies the other student with a different view of the skull, and together, this student pair forms a research team. The research teams identify the skull replica of their fossil "find" and then proceed to use a dichotomous key, and applying their knowledge of skull characters, navigate through the key and identify the skull. The dichotomous key we use has been specifically developed for use with our skull collection in which we have considered ease for student interpretation and the introduction of important evolutionary characters (Fig. 5). However, it is not a phylogenetic taxonomic key based on the chronological evolution trends or states of characters. We believe that matching two 2-D puzzles for identifying a 3-D skull and
Fig. 3 One student's drawing of the skull of a horse along with data provided by other student's drawings and interpretations of the reference collection

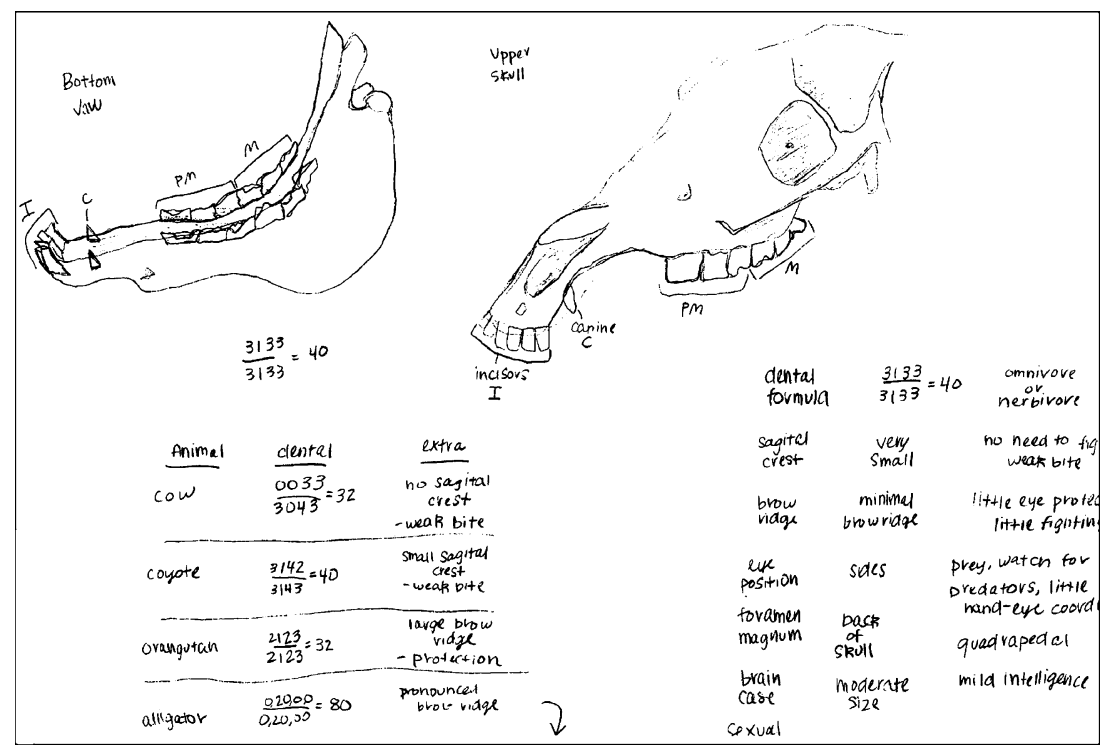


Fig. 4 a Puzzle pieces for one fossil find to be assembled and compared with other views within the classroom. b Students use their puzzles to identify the replica fossil skull that will then be identified using a taxonomic key
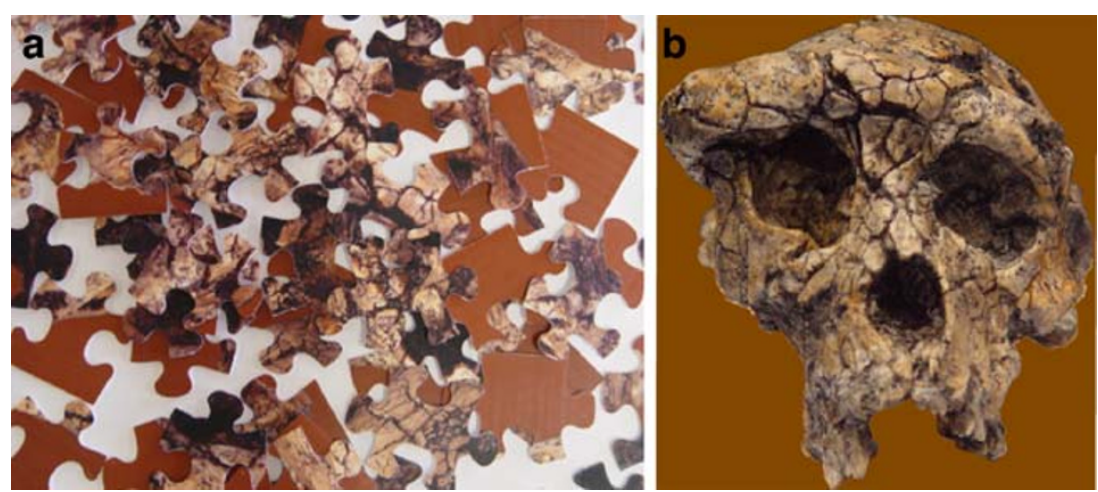

then using the dichotomous key to work with and interpret the skulls is a useful way of learning science visualization modeling skills (Gilbert 2005). Students are encouraged to handle, manipulate, observe, and measure the skull specimen in a format of discovery learning. Students record qualitative and quantitative data on the fossil skulls in line with procedures for collecting data from an extant reference skull collection to assist in their interpretations (Fig. 6). A sequence of asking questions, making
Fig. 5 A taxonomic key developed for the students to identify the fossil skulls

\section{TAXONOMIC KEY FOR HOMINIDS}

1A. Foramen magnum at angle to skull (not directly under base); spinal cord exit

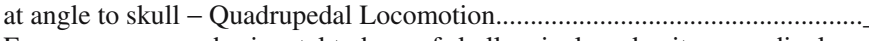
go to 2

IB. Foramen magnum horizontal to base of skull; spinal cord exit perpendicular

2A. Nasal cavity triangular go to 3

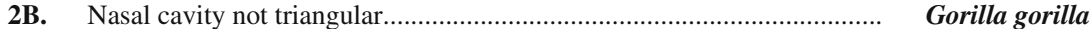

i. Sagittal crest prominent, large canine teeth............................. male

ii. Sagittal crest reduced, small canine teeth................................. female

3A. Zygomatic arch robust (width at midpoint of arch 9-16 mm

Pongo pygmaeus

3B. Zygomatic arch gracile (width at midpoint of arch 5-9 mm Pan troglodytes

4A. Sagittal crest prominent Paranthropus boisei

4B. Sagittal crest minimal or absent go to 5

5A. Cranium (length of skull from brow to ridge to lower occipital bone) small; less than $250 \mathrm{~mm}$ go to 6

5B. Cranium (length of skull from brow to ridge to lower occipital bone) large; greater than $250 \mathrm{~mm}$ go to 9

6A. Brow ridge / supraorbital torus prominent go to 7

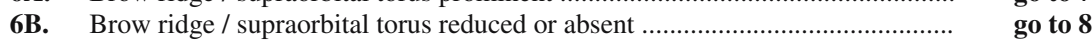

7A. Subnasal prognathism intermediate.

7B. Subnasal prognathism reduced / weak

Australopithecus africanus Sahelanthropus tchadensis

8A. Mandible length greater than $120 \mathrm{~mm}$. Australopithecus afarensis

8B. Mandible length less than $120 \mathrm{~mm}$..... Homo floriensis

9A. Brow ridge / supraorbital torus prominent

9B. Brow ridge / supraorbital torus reduced or absent go to 12

10A. Cranium (length of skull from brow to ridge to lower occipital bone) large; greater than $315 \mathrm{~mm}$

Homo neanderthalensis

10B. Cranium (length of skull from brow to ridge to lower occipital bone) small; less than $315 \mathrm{~mm}$.

go to 11

11A. Back mandibular molar width $\approx 10 \mathrm{~mm}$ or less.

11B. Back mandibular molar width $\approx 11 \mathrm{~mm}$ or more

Homo ergaster Homo erectus

12A. Mandible length $\approx 115 \mathrm{~mm}$.

Homo sapiens

12B. Mandible length $\approx 140 \mathrm{~mm}$. Piltdown Man (paleontological fraud) 


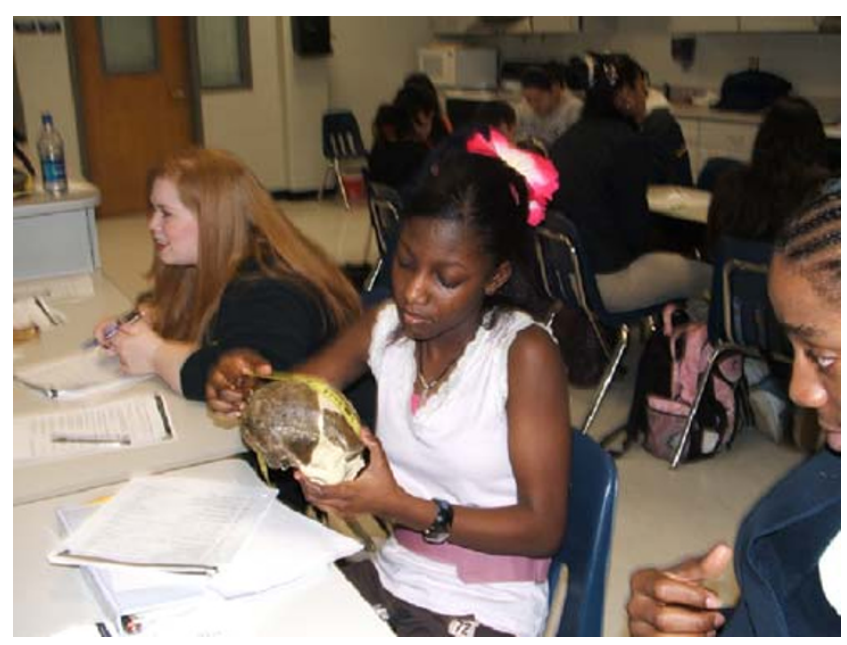

Fig. 6 A student collecting data from a replica of $H$. erectus

observations, drawings, and recording data (Fig. 7) leads to the logical formation of inferences dealing with the dentition, diet, and comparative estimates of intelligence for the observed fossils. Students also inspect the skulls to infer the social structure of hominid groups based on sexual dimorphism in skull features with respect to male/female differences in (a) size of skulls, (b) supraorbital crest, and (c) size of canine teeth.

Safari day 6: Investigating the extant and extinct skulls naturally weaves into an inquiry into the origins of hominid bipedalism. Another tier of scientific vocabulary and practice is added to the existing scaffold of knowledge, preparing students for a culminating student- driven investigation dealing with this topic. Students begin by comparing skeletal characters between humans and gorillas, and identifying the skeletal adaptations that permit either bipedalism or quadrupedalism. The angles of basicranial flexion at the foramen magnum/occipital bone of the cranium and vertebral column and the anatomy of the pelvis, femur, and knee joint are analyzed. Students apply this newly acquired knowledge to deduce the mode of locomotion of the fossils observed in the previous activity. Were the individuals bipedal or quadrupedal? Questions also arise about the primate evolutionary tree. How does this discovery (bipedal walking) shed light on the evolutionary pathways of the fossil individuals, humans and other primates such as the orangutan, gorilla, and chimpanzee? Students are prepared to think about and work on their independent research projects focusing on the six proposed hypotheses accounting for the selection of bipedalism, and yet they also now realize that there exists a fossil record of seemingly contradictory failures.

Safari day 7: Students create a phylogenetic tree to develop relationships between the observed extant and fossil skulls. They use the hallway, with each floor tile or locker representing 50,000 or 100,000 years, to place the extinct skulls along a chronological timeline (Fig. 8) covering 6-7 Ma into deep time (Catley 2006). Extant skulls (human, gorilla, orangutan, and chimpan-
Fig. 7 A sample sequence of asking questions, making observations, drawings, and recording data leading to the logical formation of inferences dealing with the dentition, diet, and comparative estimates of intelligence for the observed fossils

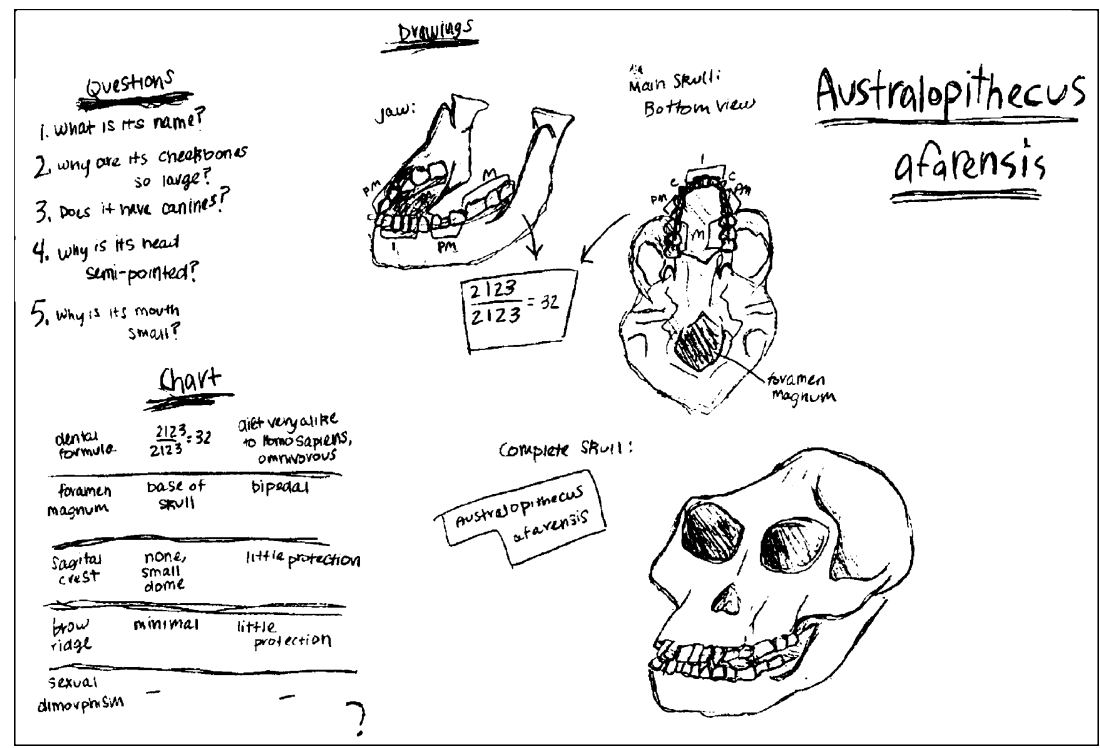




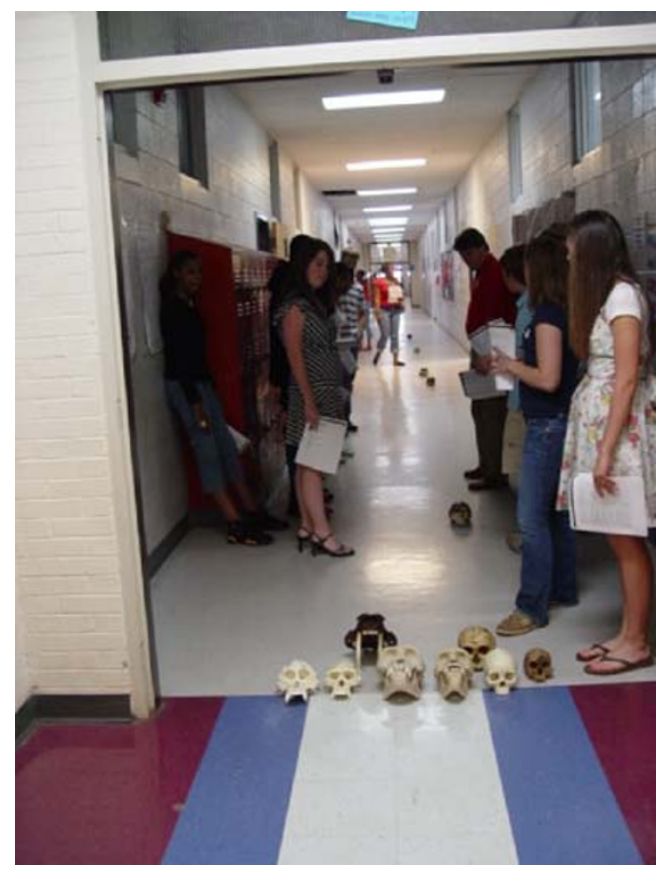

Fig. 8 Students use the hallway, with each floor tile or locker representing 50,000 or 100,000 years, to place the extinct skulls along a chronological timeline

zee) are also included in the phylogeny. Based on a collection of skull characters, students derive possible inferences as to possible evolutionary pathways. Students create a final drawing to show phylogenetic relationships. Once most have reached a consensus (not all classes have been able to reach a unanimous pathway), we introduce a new fossil find, Homo habilis, and ask them to integrate this skull into their proposed lineage; first, without knowledge of its radiometric date in geological history or where it has been found. After discussion, this information is provided, followed by further discussion.

Safari day 8-10: Up to this point, a rich environment for inquiry has been created. Students have been equipped with the investigatory powers of a scientist and the relevant vocabulary to articulate findings. In the interim, we have given students time, either as homework or in the school media center, to research their research questions accounting for the questions and hypotheses proposed for the evolution research symposium. On days 8-10, students work on their presentations. Presentation schedules are developed, and invitations are sent to parents to attend. A guide for developing a slide presentation number and kinds of slides) is given the students, and during the presentations time is given for students to ask questions or for clarifications from the speaker.

\section{Discussion}

Important learning outcomes emerge through these studentdriven experiences that can provide a model for classroom use. For instance, students recognize the relationship between observations and inferences, and recognize the importance of providing a substantial base of evidence in suggesting likely inferences. Most importantly, students discover answers to difficult questions rather than being forcefully educated by an authority figure (teacher). For example, one difficult question, How do scientists know what they know about past events, or evolution?, could potentially incite controversy in an environment bereft of student practice and experience. However, through their own experiences and knowledge construction, students are exposed to the immediate reality of foreign, ancient fossils. They grapple with the fossil evidence and come to understand that a probable picture of past events can be reconstructed based on this evidence, albeit incomplete.

The instructional approach of scaffolding student understanding provides a sensitive yet scientifically sound strategy to teaching evolutionary concepts through inquiry. Moreover, a learning environment is enriched by layering curricular topics (skeletal system, muscular system, dentition, ecological niche, animal locomotion, and evolution) to replicate experiences of practicing paleoanthropologists. In addition to learning scientific content, students become attuned to the nature of science when they base scientific conclusions on evidence, use methods other than the standard scientific method to create scientific knowledge, demonstrate creativity in asking and answering questions and forming inferences, recognizing the tentativeness and subjectivity in the scientific process, and realize that science may not be able to answer all questions. The implications of this unit are especially relevant to science teacher education in the light of the ongoing national controversy of evolution vs creationism and intelligent design, and in the light of the need to emulate scientific practices in science classrooms through inquiry learning.

We have found that full-scale replica hominid fossil skulls are critical and superior to textbook figures for providing students with opportunities for them to conduct their own hands-on investigations into hominid evolution. 
A natural and realistic question for teachers is how much will a unit such as this cost? A basic collection of replica skulls (extant and extinct) will cost $\$ 2,000$, and this may seem like a large investment. However, this is the cost of two microscopes, and skulls are a long-term and inexpensive investment per student. We are encouraging school districts to purchase the skulls for all levels (elementary, middle, and high school) for sharing throughout different curriculum units.

We have found it effective to introduce evolutionary study to students using the argument that crime scene investigators and paleoanthropologists are using similar techniques and evidence in building reliable reconstructions and explanations for past events. The reference collection of skulls for extant vertebrates permits students to make comparisons and contrasts with the extinct fossil skulls. It is in this spirit that we suggest that even after 3.2 Ma, Lucy is still not only able to tell us an important story, but she is doing it from the perspective of other very distant relatives, such as Sahelanthropus tchadensis and Orrorin tugenensis. We have found that students are anxious to help Lucy reveal her story. And through this enthusiasm, we encourage the students to appreciate and realize that there are still so many stories in the fossil record that remain to be told, and that is the most exciting aspect of finding out first, what we can learn about skulls, but there is so much more for them to add to the fossil story!
Acknowledgements We would like to acknowledge both "boneclones" and Wards Scientific as sources for the sets of replica bones and skulls used in our lessons. Our images and puzzles have been made using skulls obtained through "boneclones".

\section{References}

Ben-Ari M. Just a theory: exploring the nature of science. Amherst, NY: Prometheus Books; 2005.

Cameron D, Groves C. Bones, stones, and molecules. Amsterdam: Elsevier; 2004.

Catley K. Darwin's missing link - a novel paradigm for evolution education. Sci Ed. 2006;90:767-83.

Freeman S, Herron J. Evolutionary analysis. Upper Saddle River, NJ: Prentice-Hall; 2007.

Futuyma D. Evolution. Sunderland, MA: Sinauer Associates; 2005.

Gibbons A. The first human: the race to discover our earliest ancestors. New York, NY: Doubleday; 2006.

Gilbert J. Visualization in science education. Dordrecht, The Netherlands: Springer; 2005.

Lewin R, Foley R. Principles of human evolution. Malden, MA: Blackwell; 2004.

Lucas P. Dental functional morphology: how teeth work. Cambridge, UK: Cambridge University Press; 2004.

National Research Council. Inquiry and the national science education standards. Washington, DC: National Academy Press; 2000.

National Research Council. How students learn: science in the classroom. Washington, DC: National Academy Press; 2005.

Thomson N, Chapman S. An inquiry safari. Sci Teach. 2004;71:20-5.

Wards (2008). [www.wardsci.com].

Weber B, Vedder A. In the kingdom of gorillas. New York, NY: Simon and Schuster; 2001. 